of fotal membranes were located, indicating that the embryo may have been torn from its original implantation site when the uterus was first opened. The embryo was at the equivalent stage of development of a human embryo of about three weeks. Forebrain, nerve cord and ten somites are readily identifiable.

It was thought probable on the above evidence that in the elephant seal there is a delayed implantation such as occurs in the European badger, the American marten, the armadillo, the northern fur seal and other species. In such animals the egg develops to the blastocyst stage and then lies dormant, sometimes for months, before becoming implanted and continuing to develop.

Confirmatory evidence was discovered when the uterus of a seal killed in mid-December was sectioned and a $0 \cdot 3-\mathrm{mm}$. blastocyst was found (Fig. 2). The blastocyst was enclosed in what appeared to be the much-thickened egg membrane, which was closely applied and probably attached to the uterine mucosa. No sign of implantation was observed.

Further sectioning of elephant seal uteri taken at different times in the moulting season is now being carried out in the hope of discovering more about the early embryology. A detailed account of these findings together with other information on the sexual cycle of the elephant seal will be included in a paper now in preparation.

Biology Section,

Antarctic Division,

Department of External Affairs,

Melbourne, Australia. June 4.

\section{Varietal Reaction of Jowar to Grain Smut}

Jowar (Sorghum vulgare, L.), an important grain crop, occupies about 23 lakh acres in Uttar Pradesh, and the State stands third in its production in India. The crop is invariably attacked by a severe smut disease caused by Sphacelotheca sorghi (Link) Clinton. It causes usually $2-5$ per cent infection in the crop; but as high as 65 per cent infection has been recorded in some fields. On the basis of 2 per cent loss, the grain smut is responsible for a loss of more than five thousand tons of grain or 15.5 lakhs of rupees in terms of money annually. Considerable work has been done in Bombay and Uttar Pradesh as well as in other States of India on the control of the smut by fungicidal seed treatments; but there seems to be no report available on the resistant varieties of jowar to grain smut in India. The work on testing some varieties of jowar against grain smut was therefore started in 1950 and continued up to 1952 .

Twenty-seven promising varieties or cultures of jowar were tested for their resistance towards grain smut. The seeds of the varieties or cultures were first moistened with water and then thoroughly mixed with smut spores (mixed collection from all over the United Provinces) in the proportion of $1: 100$ and were sown on three different dates at fortnightly intervals to give varying conditions of environment. The percentage of smut was calculated by counting healthy and smutted heads in each variety or culture. They can be grouped as follows, according to average smut infection shown by them.
Resistant

(Below 1 per cent infection)

Moderately resistant

(Below 5 per cent infection)

Susceptible

(Below 15 per cent infection)

Very susceptible

(Above 15 per cent infection)

$31 B, 4101$

$4403,4404 A$, S.A.7005, 4801(a), $4403 B$

$30 D, 4108,10 E . K ., 4404 B$

S.A.5155-5, 4801, 48/2, $4801(b)$, $4404 B-A, 51 / 3$

$5 T, 8 B, 30 C, 18,4106 B, 4109$,

Most of the very susceptible varieties showed 30 65 per cent infection.

It is evident from the results that the most popular varieties of jowar in the State, namely, $8 B$ and $5 T$, are highly susceptible. The two cultures $31 B$ and 4101 proved to be highly resistant. Five cultures proved moderately susceptible. This information may prcve useful in evolving varieties of jowar by combining desirable grain characters with resistance to grain smut.

We are grateful to Dr. T. R. Mehta, economic botanist (oilseeds, millets and pulses) to the Government, United Provinces, Kanpur, for the supply of jowar varieties and cultures employed during the investigation.
P. R. Mefta
Babu SINGH
S. C. Mathur
S. B. SINGH

Laboratory of Plant Pathologist to the

Government of the United Provincés,

Kanpur.

May 20.

\section{Chromosomes of Phylloglossum drummondii, Kunze}

Phylloglossum, the monotypic genus of the Lycopodiaceæ; is confined to Australia and New Zealand, being represented by the single species, Phylloglossum drummondii. Much attention has been given to the morphology and anatomy of the plant over the past fifty years by Bower, Thomas, Osborn and other workers, and there has been much speculation on the evolutionary interpretation of its structure. A comprehensive review of all this work has been given, recently, by Hackney ${ }^{1}$; but at no time has the cytology of the plant been discussed.

Manton ${ }^{2}$ deals in detail with the cytology of the lycopods of Europe only, and so does not include a study of the chromosomes of Phylloglossum.

It seems fitting, then, to record the chromosome number and arrangement in Phylloglossum drummondii observed in material collected at Heathmont, Victoria, in 1952. The stroboli were fixed in aceticalcohol and preparations made by using the ironaceto-carmine squash technique.

Fig. 1 shows a metaphase plate of the first meiotic division in polar view with 246 bivalents and 10 univalents, giving a diploid number of 502. Fig. 2 is a camera lucida drawing of Fig. 1. With such a large number it is difficult to obtain the necessary 'spread' of the chromosomes to be certain of the count; but, allowing for a good margin of error in observation, the haploid number is not less than 250 and not more than 255. The presence of univalents (marked $a$ in Fig. 2 was verified by observations of unpaired chromosomes at the pachytene stage of meiosis. 